\title{
Woolly hair-palmoplantar keratoderma syndrome
}

INSERM

\section{Source}

INSERM. (1999). Orphanet: an online rare disease and orphan drug data base. Woolly hair-palmoplantar keratoderma syndrome. ORPHA:420686

Woolly hair-palmoplantar keratoderma syndrome is a very rare, hereditary epidermal disorder characterized by hypotrichosis/woolly scalp hair, sparse body hair, eyelashes and eyebrows, leukonychia, and striate palmoplantar keratoderma (more severe on the soles than the palms), which progressively worsens with age. Pseudo ainhum of the fifth toes was also reported. Although woolly hair-palmoplantar keratoderma syndrome shares clinical similarities with both Naxos disease and Carvajal syndrome, cardiomyopathy is notably absent. 